\title{
Divergent Selection and Then What Not: The Conundrum of Missing Reproductive Isolation in Misty Lake and Stream Stickleback
}

\author{
Katja Räsänen, ${ }^{1,2}$ Matthieu Delcourt, ${ }^{1,3}$ Lauren J. Chapman, ${ }^{1}$ and Andrew P. Hendry ${ }^{1}$ \\ ${ }^{1}$ Redpath Museum and Department of Biology, McGill University, 859 Sherbrooke Street. W, Montreal, QC, Canada H3A 2 K6 \\ ${ }^{2}$ Department of Aquatic Ecology, Eawag and ETH-Zurich, Institute of Integrative Biology, Ueberlandstraße 133, \\ 8600 Duebendorf, Switzerland \\ ${ }^{3}$ Department of Biology and Centre for Advanced Research in Environmental Genomics, University of Ottawa, Ottawa, \\ ON, Canada K1N 6N5
}

Correspondence should be addressed to Katja Räsänen, katja.rasanen@eawag.ch

Received 1 July 2011; Accepted 28 October 2011

Academic Editor: Rui Faria

Copyright ( $\odot 2012$ Katja Räsänen et al. This is an open access article distributed under the Creative Commons Attribution License, which permits unrestricted use, distribution, and reproduction in any medium, provided the original work is properly cited.

In ecological speciation, reproductive isolation evolves as a consequence of adaptation to different selective environments. A frequent contributor to this process is the evolution of positive assortative mate choice between ecotypes. We tested this expectation for lake and inlet stream threespine stickleback (Gasterosteus aculeatus) from the Misty system (Vancouver Island, Canada), which show strong genetically based adaptive divergence and little genetic exchange in nature. This, and work on other stickleback systems, led us to expect positive assortative mating. Yet, our standard "no-choice" laboratory experiment on common-garden fish revealed no evidence for this_-despite divergence in traits typically mediating assortative mating in stickleback. These results remind us that divergent natural selection may not inevitably lead to the evolution of positive assortative mate choice. The apparent lack of strong and symmetric reproductive barriers in this system presents a conundrum: why are such barriers not evident despite strong adaptive divergence and low gene flow in nature?

\section{Introduction}

Ecological speciation occurs when divergent selection causes adaptive divergence that then causes the evolution of reproductive isolation [1]. This process now has considerable empirical support across a wide range of taxa [1-3]. Some of the strongest support comes from laboratory studies showing that mating is more frequent between individuals from similar environments than between individuals from different environments [4-10]. However, some recent work suggests that positive assortative mate choice (henceforth PAMC) does not always evolve in response to divergent selection [11-15]. These results suggest the importance of other modifying factors that influence the evolution of PAMC-even when divergent selection and adaptive divergence are present $[16,17]$. Insight into these modifying factors can be gained from empirical systems within which the strength of PAMC varies among population pairs (e.g., $[18,19])$.
Threespine stickleback (Gasterosteus aculeatus Linnaeus) are a useful system for investigating ecological speciation because they show dramatic adaptive divergence between populations inhabiting different environments, hereafter referred to as "ecotypes" [20-22]. This adaptive divergence appears linked to PAMC in experimental studies on a number of ecotype pairs: benthic versus limnetic $[5,8,9$, 23-25], fresh water versus anadromous $[7,26]$, and mud versus lava [27]. By contrast, PAMC was not found in recent comparisons of fresh water versus anadromous [28] and lake versus stream stickleback [29]. Our study will further explore the lake/stream situation.

Several characteristics make lake/stream stickleback suitable for the study of ecological speciation. First, lake/stream population pairs have evolved independently in many different watersheds following postglacial colonization by similar marine ancestors [30-33]. Second, lake/stream stickleback often show genetically based adaptive divergence in phenotypic traits related to foraging, swimming, and 
predator avoidance $[31,32,34-40]$. Third, lake/stream stickleback are often parapatric, and different population pairs show different levels of gene flow. In particular, the lake/ stream pairs that show the greatest adaptive divergence are also those that show the lowest gene flow at neutral markers $[31,33,38,39,41]$. This last pattern is often used to infer progress toward ecological speciation, but it has two limitations: (1) cause and effect are hard to disentangle [42] and (2) neutral markers are often insensitive indicators of progress toward ecological speciation [43-45]. It is therefore important to also test for specific reproductive barriers thought to have an ecological basis [16].

Our investigation of reproductive barriers in lake/stream stickleback focuses on populations found in the Misty watershed, Vancouver Island, Canada. The Lake and Inlet stream populations in this watershed show strong genetically based adaptive divergence and very low gene flow in neutral markers [37, 38, 40, 46, 47]. They are clearly under strong divergent selection and so might be expected by the theory of ecological speciation to exhibit PAMC. Yet our first test for this possibility did not find any evidence for this [29]. However, the experimental design used in [29] (i.e., pairs of directly interacting males between which females could choose) was quite different from the standard "no-choice" designs that have so frequently revealed PAMC in stickleback (Table S1 of the Supplementary material available online at doi:10.1155120111902438). As experimental setup and environmental conditions may influence the outcome of mate choice studies in various ways (e.g., [48-50]), it is important to repeat these tests in multiple different conditions. We therefore here revisit the question by analyzing mate choice experiments done with the "no-choice" design. This allows us to (1) see if the apparent lack of PAMC between Misty Lake and Inlet stickleback is robust to experimental methods, and (2) make more direct comparisons to previous work on other stickleback systems. In addition, whereas the study by Raeymaekers et al. [29] investigated mate choice of lake and inlet females towards lake, inlet, and hybrid males, we include a "control" comparison of Misty Lake fish versus Misty Outlet stream fish. These two populations show very low adaptive divergence and very high gene flow in nature $[32,38,39,41,46,47,51]$. This comparison can therefore serve as a low divergence lake/stream "control" in which we have no reason to expect PAMC - in contrast to the highdivergence comparison of Misty Lake versus Misty Inlet.

Some other features of our study design are important to note. First, our experimental fish were reared for their entire lives in a common garden environment, as opposed to being collected from the wild. This was done to reduce the chance that observed mate choice patterns result from environmental (nongenetic) effects, such as imprinting, maternal effects, prior experience, and/or other forms of plasticity (e.g., [48-50]). Second, we presented individual males of each type (Lake, Inlet, and Outlet) to females of all three types, which should increase inferential ability by controlling for variation among individual males. Our main prediction is that if PAMC contributes to reproductive isolation in the Misty watershed, we should see PAMC between the strongly divergent Lake and Inlet fish, but not between the phenotypically and genetically similar Lake and Outlet fish: Inlet females should prefer Inlet males and choose against both Lake and Outlet males, whereas both Lake and Outlet females should prefer Lake and Outlet males and choose against Inlet males.

\section{Materials and Methods}

2.1. Collections and Rearing. In June, parental fish were collected from the Misty system at one Lake site (site 1), one Inlet site (site 4, ca. $2.6 \mathrm{~km}$ from the lake), and one Outlet site (site 4 , ca. $0.85 \mathrm{~km}$ from the lake) (for a map, see [47]). Standard artificial crossing methods [52] were used to generate eight full sibling families for the Lake population, seven for the Outlet, and four for the Inlet. The smaller number of Inlet families was due to limited availability of mature females during the collection period. Fertilized eggs were transferred to our laboratory at McGill University, Montreal, where rearing proceeded in family-specific groups in 20-100 L tanks (aquaria), with a given family split into multiple tanks randomized across four climate-controlled chambers. Fish were maintained at roughly equal densities (25 fish per $100 \mathrm{~L}$ ), and families were never mixed. Males and females could not be visually discriminated as juveniles, and so were raised together. As fry, the fish were initially fed live brine shrimp nauplii (Artemia sp.) and then later switched to a mixed diet of live brine shrimp nauplii, frozen blood worms (Chironomid sp.), and frozen brine shrimp. During the conditioning period (see below), the fish were fed a mixture of live brine shrimp nauplii and live blackworms (Lumbriculus sp.).

Through April of the following year, the fish were reared under constant "summer" conditions (16:8 L:D photoperiod, $17^{\circ} \mathrm{C}$ ), after which they were switched to "winter" conditions $\left(8 \mathrm{~L}: 16 \mathrm{D}, 12^{\circ} \mathrm{C}\right)$. The different chambers were then switched back to "summer" conditions at various times from September through October to ensure the availability of fish in breeding condition over an extended period of time. No nesting material was provided in the rearing tanks, thus preventing breeding activities prior to the experimental trials described below. Fish were used in the experiment once they reached sexual maturity, as indicated by nuptial color in males and distended abdomens in females. This laboratory cohort of fish has been previously analyzed for morphological traits [46], male courtship [51], and swimming performance [40] and represent the parental generation for the fish used in the experiments of $[29,53]$.

2.2. The Experiment. Eighteen experimental tanks (102 L; length $=92 \mathrm{~cm} \times$ width $=32 \mathrm{~cm} \times$ depth $=39 \mathrm{~cm}$ ), each filled with water to a depth of $20 \mathrm{~cm}$, were set up in a shaded green house at McGill University. The bottom of each tank was covered with dark gravel, and one end was additionally covered with a patch of sand (length $=15 \mathrm{~cm} \times$ width $=$ $32 \mathrm{~cm} \times$ depth $=2.5 \mathrm{~cm}$ ). Dead plant matter collected from Misty Lake, plus a small amount of green algae and grass clippings, was provided as nest building material because pilot studies with wild-caught fish showed that this material was readily used for nest building by all ecotypes. All sides 
of the tanks were covered with brown packing paper to minimize disturbance.

The experiment was run under "summer" conditions $\left(16 \mathrm{~L}: 8 \mathrm{D}, 18^{\circ} \mathrm{C}\right)$. A single male was placed into each tank and was then stimulated to build a nest by periodic exposures (15 minutes once or twice per day) to a gravid female. These "stimulus" females were chosen haphazardly from the rearing tanks, were presented in a clear glass jar with a mesh lid, and were not used in the experimental trials described below. A male was assumed to be ready for a trial when he showed nuptial coloration and guarded a nest. Males that did not build nests within a week were not used in the experiment. As all males faced multiple randomly chosen females during the stimulation period, it is unlikely that the identity of these females would have biased male behavior during the mating experiment. After a male was removed from a tank, the tank was cleaned, all materials were replaced, and a new male was added.

Prior to the experimental trials, the fish had been reared under a combination of natural and full-spectrum fluorescent light (Vita-Lite $40 \mathrm{~W}$, Duro-Test, Canada). The Misty system, however, is highly tannic [37] and is dominated by red light (confirmed by spectroradiometer measurements; N. P. Millar, unpubl. data). We mimicked these lighting conditions during the experimental trials by filtering fullspectrum fluorescent light through a filter (rust, code 777, Lee Filters, England) placed above each tank.

An experimental trial was initiated by allowing a gravid female to swim freely from a clear plastic box into a male's tank. Subsequent male-female interactions were then videotaped with a digital camcorder (Canon ZR90; Canon, see [51] for details). Video recording stopped after 45 minutes or after the female entered the nest, whichever came first. After each mating trial, ripeness of the eggs of each female was confirmed by gentle pressure on her belly (ripe eggs require only gentle pressure to extrude). Any trial with a nonripe female was disregarded, and the male was tested again with another female of the same ecotype after a lag time of at least three hours.

Each male was sequentially exposed to three females, one of each ecotype, at minimum intervals of three hours. The sequence in which different female types were introduced to a male was varied among males so as to achieve a similar sequence distribution across the male ecotypes. Some deviations from a perfectly balanced design occurred when gravid females of the right type were not available at the right time. Nine males were therefore tested with only two female ecotypes and one male with only one female ecotype. Excluding these males did not influence our conclusions, and so all males are included in the analyses presented below. Each female was used in only a single trial, and males and females from the same family were not combined in any trial.

In order to standardize the conditions experienced by one male across all three female types, we prevented actual spawning during the experimental trials. This was done by using long forceps to gently squeeze the female's caudal peduncle if she entered the nest, which always precipitated her immediate departure. After the trials for a given male or female were complete, the fish was anesthetized with buffered
MS222, measured for standard length, and photographed on a grid-ruled background (Nikon coolpix 5400, Nikon Inc.). A total of 111 trials were conducted on 43 males. Total numbers of trials for the Inlet (I), Outlet (O), and Lake (L) ecotype combinations were $\mathrm{II}=12, \mathrm{IL}=13, \mathrm{IO}=14, \mathrm{LI}=12, \mathrm{LL}=$ $14, \mathrm{LO}=13, \mathrm{OI}=12, \mathrm{OL}=11$, and $\mathrm{OO}=10$ (male origin indicated by first letter, female origin by the second letter).

2.3. Response Variables. Our three measures of female behavior were (1) head up (the female inclines her head and body upwards in a roughly $45^{\circ}$ angle), (2) nest inspection (the female places her snout in the nest opening), and (3) nest entry (the female enters the nest). These variables represent progressive stages during the mating sequence. Head up indicates female responsiveness, and nest inspection indicates a transition between female responsiveness and female choice. Nest entry indicates female choice and is strongly correlated with spawning (pers. obs). (Note. Females can skip any of these steps.) Each of these variables has been used in previous work on stickleback (e.g., $[25,52,54]$ ), and they are here treated as binomial variables (i.e., whether or not a given female showed a given response when interacting with a given male).

To test whether mating is nonrandom with respect to phenotype, we analyzed female mate choice in relation to body size and male courtship. Body size is of particular interest as it has been suggested to be a "magic trait" driving ecologically mediated PAMC in stickleback through a "mate with your own size" rule $[7,8,24]$. Our two body size metrics were relative size difference (male size minus female size, henceforth RSD) and absolute size difference (larger sex minus smaller sex, henceforth ASD) - both indicative of size assortative mating. (We also tested for an effect of absolute male size, but as that had very minimal effects and did not alter any of our conclusions, we do not present the results here.) Our two measures of male behavior were aggression and display toward females. Aggression and display were both composite variables calculated as the sum of the frequencies of individual behaviors that males showed within each of these behavioral types during the first 15 minutes of each trial (for details see [51]). As the aim of the male courtship analyses was to estimate ecotype-specific male behavior, only the first 15 minutes were used to reduce bias from female behaviors on male behaviors. Both aspects of behavior are thought to influence mate choice in stickleback [55-57] and differ among the ecotypes within the Misty system, particularly by Lake (and Outlet) males showing more "aggressive" behaviors than Inlet males do [51].

2.4. Statistical Analyses. All statistical analyses were conducted in SAS 9.2 (SAS Institute, Inc.). Female behaviors were analyzed with generalized linear mixed models (Proc glimmix) using Maximum likelihood models with a Laplace approximation, binomial error structure, and a logit link function [58]. As an immediate test for PAMC, we first ran "ecotype models" (one for each female response variable) that included the fixed effects of male ecotype, female ecotype, and their interaction. In these models, random effects included male identity (nested within male ecotype) 
and the intercept, but not family (the data were insufficient to do so for binomial response variables). Also not included in the analyses presented here was the order of presentation of female ecotypes to a given male because this term was never significant. Adjusted post hoc Tukey tests based on least square means were used to assess pairwise differences among different ecotypes when relevant. To strengthen our conclusions, we confirmed our results for nest entry (the core measure of mating isolation) also in two other ways. First, by scoring each female response variable from 0 (none of the responses) to 3 (nest entry alone or together with headup and/or nest inspection) and conducted a generalized linear mixed model with an ordered multinomial response. Second, we treated both lake and outlet fish as the same ecotype ("lake") and analyzed the ecotype model comparing Inlet versus "Lake". However, as the results in both of these analyses were similar to our present analyses, these results are not further reported.

We next considered divergence in traits (body size and male behavior) that might influence mating patterns. In our previous paper [51], we analyzed male behavior in more detail, but not its influence on female preferences (which we do here). As a few males included in [51] were not included in our mating trials, we here confirm ecotype specific trait values and their statistical main effects (Table 2 and Table S2). Body size (log-transformed) and male behaviors (square-root-transformed) were analyzed separately. Body size divergence (individual standard length) among ecotypes was analyzed within each sex with mixed model analyses of variance (Proc mixed), where fixed effects were male (or female) ecotype, and family (nested within ecotype) (nesting being possible for the continuous data used here). Male behavioral traits were aggression (frequency of aggressive behaviors during a given mating trial) and display (frequency of display behaviors during a given mating trial). Finally, we ran "covariate models" to test whether mating is nonrandom with respect to male phenotype, and whether female ecotypes have diverged in preferences for body size and male behavior. The two body size metrics used as covariates were RSD and ASD, and the two male behavior variables were rates of aggression and display, as defined above. As for the ecotype models, these covariate models included male identity as a random effect (subject), but did not include family effects or the order of presentation of female ecotypes to males. Two modifications to the data were necessary in these covariate models. First, in analyses of head up and nest entry one outlier had to be removed to achieve convergence. Second, a few missing values for body size $(N=3)$ or behavior $(N=1)$ had to be estimated from the ecotype means. These modifications had no effect on our conclusions.

Covariate model analyses started with full models that included fixed effects of male and female ecotype, male phenotype covariates (behaviors and body size), and all two-way interactions between female ecotype and male phenotype. We then generated reduced models by removing sequentially nonsignificant $(P>0.1)$ terms involving covariates. Because display and aggression were strongly correlated and distinct among the male ecotypes, covariate models including both display and aggression, or male ecotype $\times$ female ecotype interactions, showed multicollinearity and reduced model stability. We therefore ran four sets of covariate models, each containing male ecotype, female ecotype, and female ecotype $\times$ covariate interactions and two covariates: (a) display and RSD, (b) display and ASD, (c) aggression and $\mathrm{RSD}$, or (d) aggression and ASD, but excluding the male ecotype $\times$ female ecotype interaction. Although we do not conduct formal model comparisons [59], but run several models on the same data set, we report AICc scores for the ecotype models and for the final (reduced) covariate models to allow some context to their relative explanatory power while discounting for model complexity [59]. Here those models having clearly lower AICc values were considered to have stronger support [59].

2.5. Literature Survey. To allow more direct comparisons of our results with those from other studies, we also surveyed the published literature for studies that have explicitly tested for PAMC between divergent threespine stickleback. Here we included studies that used comparable experimental methodology (either a choice or no-choice setting) and response variables (nest inspection and nest entry/spawning). The details for this survey are given in Table S1.

\section{Results}

3.1. Ecotype Models: Testing for PAMC. Neither head up nor nest inspection rates depended on male ecotype, female ecotype, or the male ecotype $\times$ female ecotype interaction (Figures 1(a) and 1(b), Table 1(a)). Nest entry was marginally influenced by male ecotype, and significantly by female ecotype, but not by a male ecotype $\times$ female ecotype interaction (Figure 1(c), Table 1). Outlet males tended to have higher mating success than either Inlet or Lake males (Figure 1(c)); however, these effects were not significant after Tukey adjustment (all pairwise $P>0.1$ ). Inlet females were more likely to mate than either Lake (Tukey $P=0.044$ ) or Outlet females (Tukey $P=0.087$, Figure $1(\mathrm{c})$ ). Thus, genetic differences between ecotypes may exist in their propensity to solicit nest entry (males) or enter nests (females), but these differences did not generate PAMC.

3.2. Trait Divergence. Both for males and females, Lake and Outlet fish were similar in size and larger than Inlet fish (Table 2). In the between-type mating trials, Inlet fish therefore tended to be smaller than Lake or Outlet fish (combinations IL, LI, IO, and OI in Figure 2). Confirming results from Delcourt et al. [51], a significant male ecotype effect in aggression and display, and a near significant female ecotype effect in display, (Table 2) was present because Lake and Outlet males were more aggressive but displayed less than Inlet males and because Inlet females tended to elicit more displays from males than did Lake or Outlet females (Table 2). Neither RSD nor ASD had a significant effect on male aggressive behavior (both $P>0.2$, Table S2), whereas RSD had a significant effect on male display behavior: males displayed more towards relatively smaller females $(\beta \pm$ S.E.: $1.925 \pm 0.662, P=0.005)$. However, even correcting for 


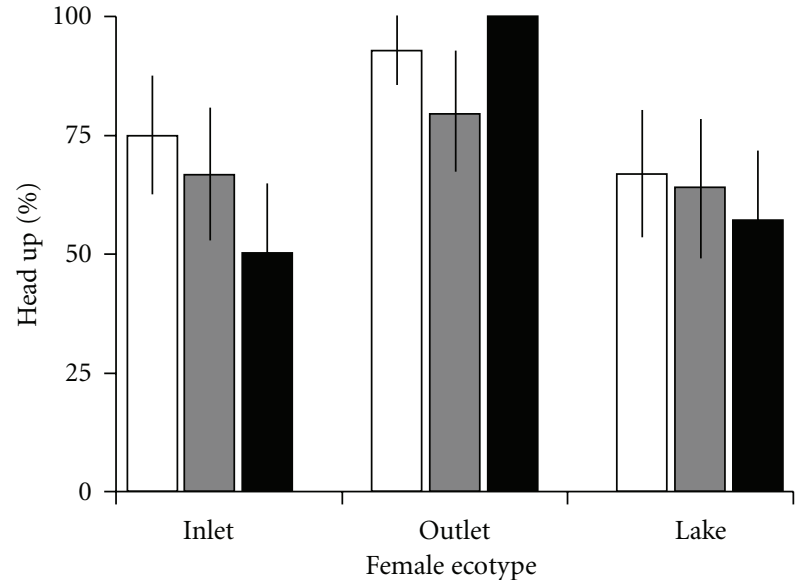

Male ecotype

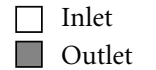

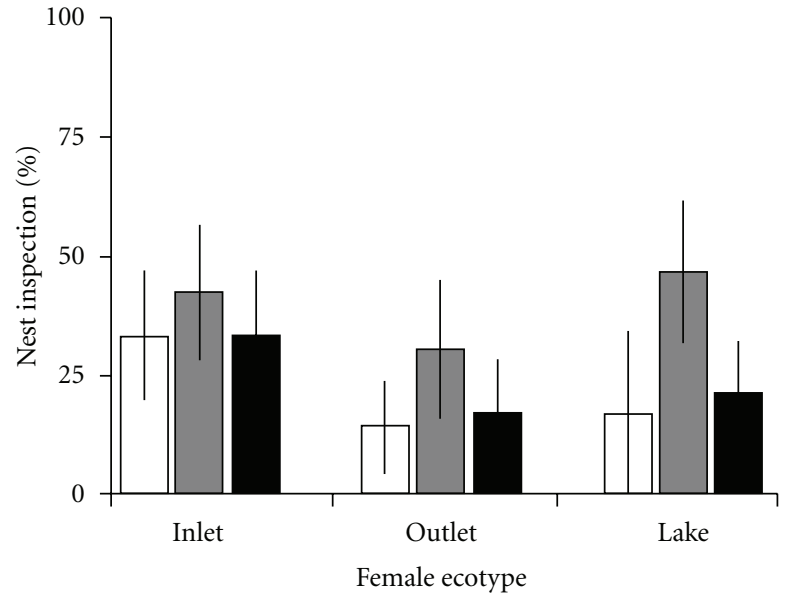

Male ecotype

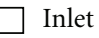

Outlet (a)

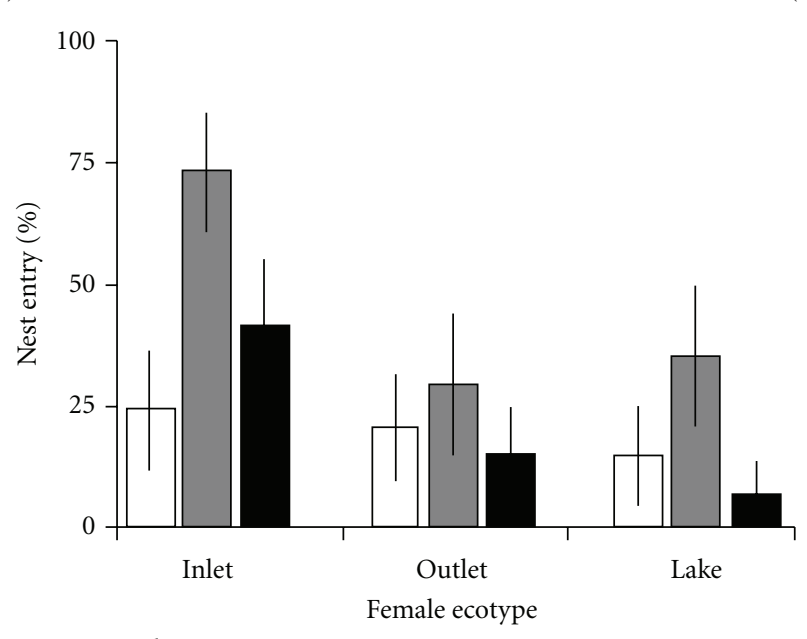

Male ecotype

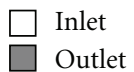

(b) 
TABLE 1: Generalized linear mixed model results for (I) ecotype and (II) covariate models testing for effects of male ecotype (meco), female ecotype (feco), and relevant covariates on head up, nest inspection, and nest entry. Mid stands for male identity. Covariates included in the initial full models were (a) display and RSD, (b) display and RSD, (c) aggression and ASD, or (d) aggression and ASD. Ecotype model and final (reduced model) AICc are given to allow inference of relative support of different models, whereby lower (difference $>2)$ is better [59]. See Table 3 for covariate slopes. Significant effects are highlighted in bold and marginally significant $(P<0.1)$ in italics.

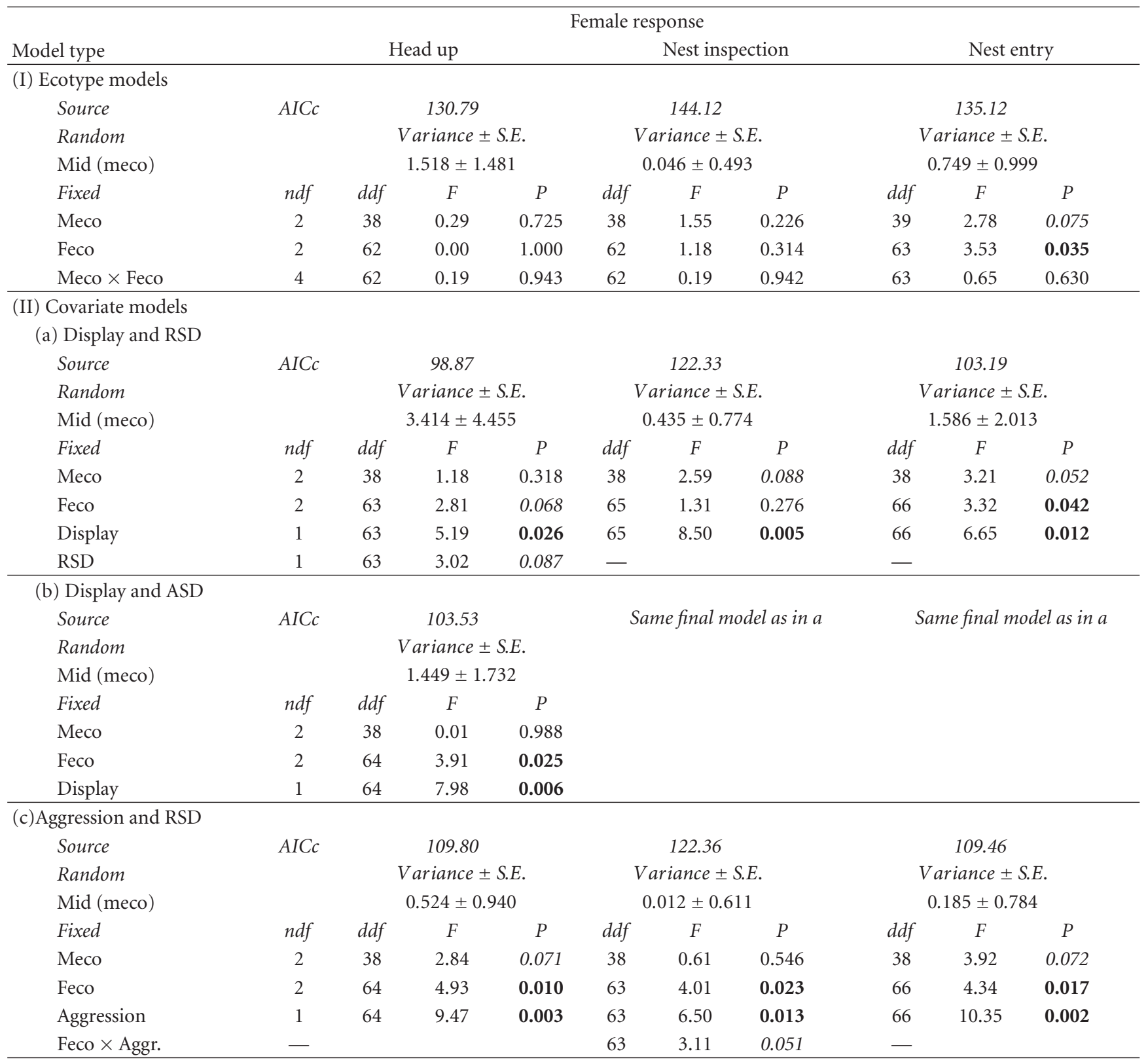

(d) Aggression and RSD

In all cases same final models as in $c$

the covariate models (i.e., Inlet females were more likely to enter nests and Outlet males to solicitate more nest entries, Figure 1 and Table 1), though the pairwise differences were not statistically significant after Tukey adjustment (Table 3).

3.4. Summary of Main Findings. Taken together our analyses on female mating preferences, and those on male courtship behavior (see also [51]), yielded five basic conclusions. First, there is no evidence for PAMC among the ecotypes. Second,
Lake and Outlet males show more aggressive courtship [51] than Inlet males, but males of all three ecotypes display more towards relatively smaller (Inlet) females. Third, female mate choice was nonrandom with respect to male phenotype: some covariates were highly significant and the covariate models clearly had more support (much lower AICc scores) than did the ecotype models. Fourth, females tended to differ in trait preferences: Lake and Outlet females tended to prefer more aggressive males (nest inspection), but this was not 


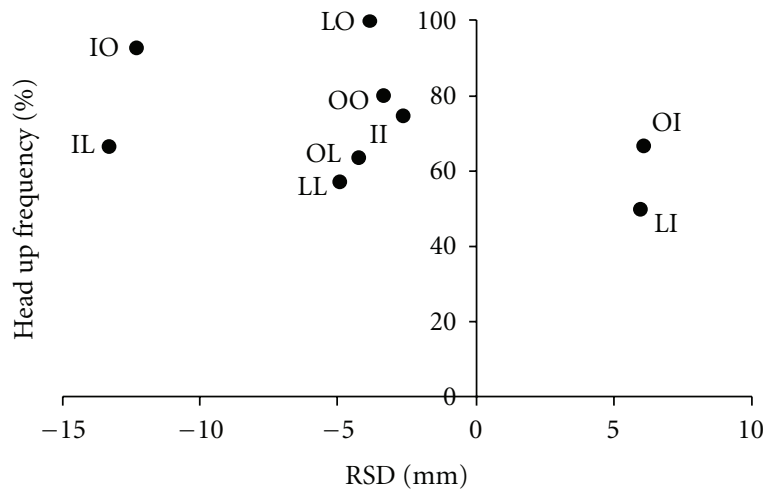

(a)

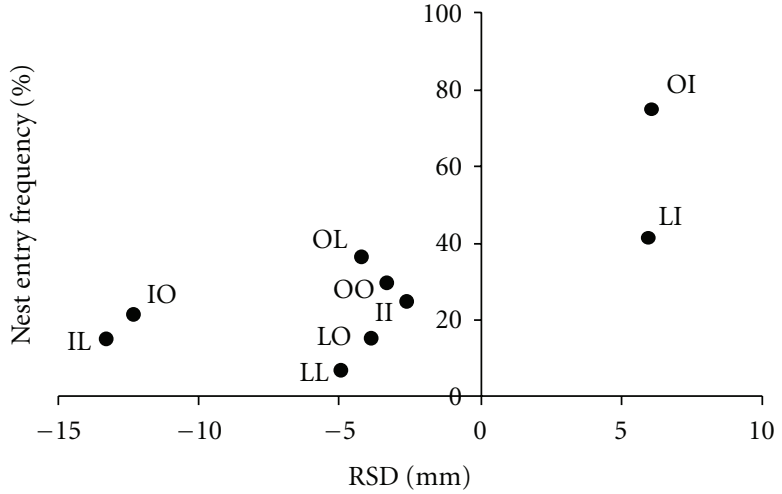

(b)

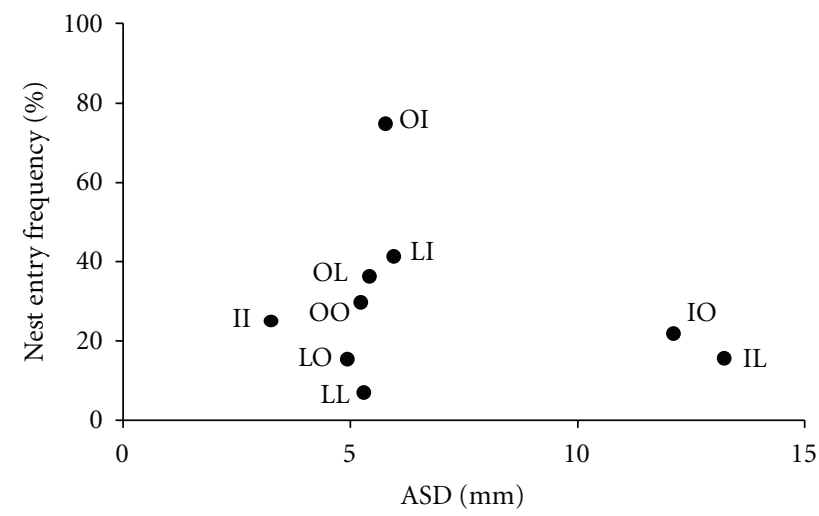

(c)

FIGURE 2: The relationships between relative (RSD) or absolute (ASD) body size difference of males and females and head up (a) or nest entry $(b, c)$ frequencies in nine ecotype combinations of Misty threespine stickleback. Each dot represents the within combination average (\%) against the size difference (RSD: male length minus female length and ASD: larger sex minus smaller sex). The ecotype combination is given in letters (I: Inlet, O: Outlet, L: Lake, first letter refers to male ecotype, second to female ecotype). See Tables 1 and 3 for covariate model test statistics.

TABLE 2: Ecotype-specific LS means \pm S.E for body size ( $\mathrm{mm}$, back transformed values with upper and lower S.E. in brackets) and sqrt (male behaviour) for Misty Inlet (I), Outlet (O), and Lake (L) stickleback, with ecotype main effects and Tukey adjusted pairwise comparisons.

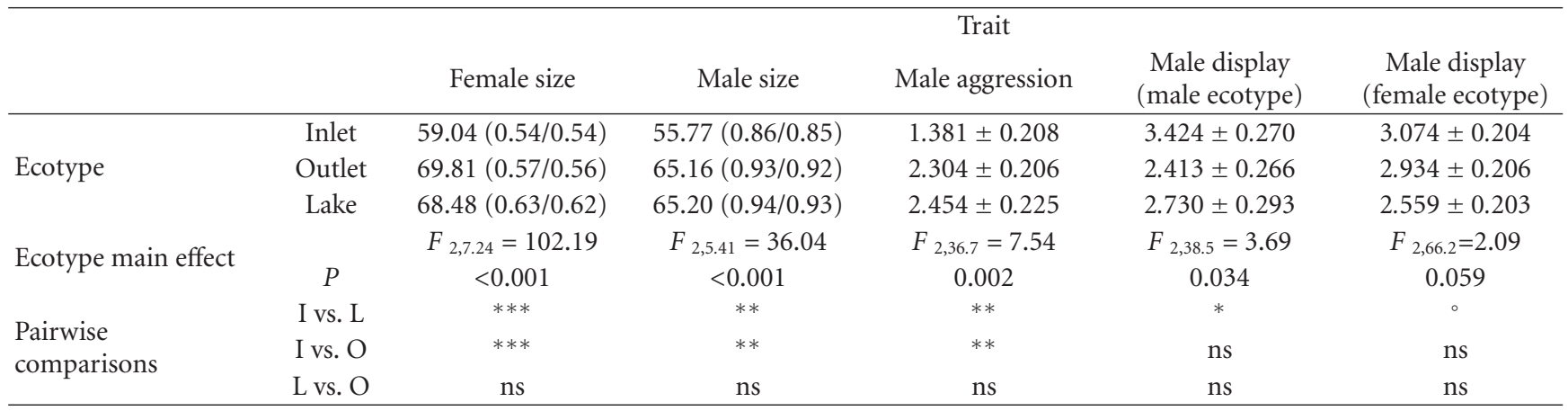

$P:^{\circ}<0.1, *<0.05, * *<0.01, * * *<0.001, \mathrm{~ns}>0.1$.

seen for Inlet females. Fifth, there was no evidence for size assortative mate choice: female responses were only weakly affected by gender differences in body size (effect of RSD on head up).

The survey of other PAMC tests in stickleback (Figure 3 and Table S1) revealed that the mating frequencies in our study fell within the range of those in other studies, though being on the lower end for nest inspection. Moreover, in contrast to most other studies, nest entry rates where somewhat higher for different ecotype matings than same ecotype matings in our study.

\section{Discussion}

We found no evidence of positive assortative mate choice (PAMC) between lake and stream stickleback from the 
TABle 3: Ecotype main effect LS means \pm S.E. and covariate slopes \pm S.E. for head up, nest inspection, and nest entry in the Misty Lake (L), Inlet (I), and Outlet $(\mathrm{O})$ three spine stickleback. The values are from final (reduced) covariate models in Table 1. For covariate effects, common slopes are given when there was no significant female ecotype $\times$ male trait interaction, whereas female ecotype specific slopes are given when these interactions were at least nearly significant. Models refer to models with (a) display and RSD, (b) display and ASD, (c) aggression and RSD, or (d) aggression and ASD as covariates in initial full model, with results of Tukey adjusted pairwise comparisons given below.

\begin{tabular}{|c|c|c|c|c|}
\hline \multirow[b]{2}{*}{ Model } & & \multicolumn{3}{|c|}{ Female response } \\
\hline & & Head up & Nest inspection & Nest entry \\
\hline \multicolumn{5}{|l|}{ (a) Display and RSD } \\
\hline \multicolumn{5}{|l|}{ Ecotype main effects } \\
\hline \multirow{3}{*}{ Female ecotype } & Inlet & $2.556 \pm 1.317$ & $-0.926 \pm 0.458$ & $-0.437 \pm 0.353$ \\
\hline & Outlet & $4.451 \pm 1.701$ & $-1.905 \pm 0.591$ & $-2.419 \pm 0.914$ \\
\hline & Lake & $0.945 \pm 0.821$ & $-1.034 \pm 0.477$ & $-2.349 \pm 0.841$ \\
\hline \multirow{3}{*}{ Pairwise comparisons } & I vs. L & ns & ns & $\circ$ \\
\hline & I vs. O & ns & ns & $\circ$ \\
\hline & L vs. O & $\circ$ & ns & ns \\
\hline \multirow{3}{*}{ Male ecotype } & Inlet & $0.728 \pm 1.076$ & $-2.388 \pm 0.745$ & $-3.651 \pm 1.318$ \\
\hline & Outlet & $3.550 \pm 1.471$ & $-0.470 \pm 0.472$ & $0.129 \pm 0.637$ \\
\hline & Lake & $3.682 \pm 1.724$ & $-1.389 \pm 0.523$ & $-1.684 \pm 0.755$ \\
\hline \multirow{3}{*}{ Pairwise comparisons } & I vs. L & ns & ns & ns \\
\hline & I vs. O & ns & $\circ$ & $*$ \\
\hline & L vs. O & ns & ns & ns \\
\hline \multirow{2}{*}{ Slopes } & Display & $1.998 \pm 0.877^{*}$ & $0.931 \pm 0.319^{* *}$ & $1.622 \pm 0.629^{*}$ \\
\hline & RSD & $-6.768 \pm 3.898^{\circ}$ & - & - \\
\hline
\end{tabular}

(b) Display and ASD

Ecotype main effects

Female ecotype

Slopes

(c) Aggression and RSD

Ecotype main effects

Female ecotype

Male ecotype

Pairwise comparisons

Slopes

Female ecotype

$\begin{array}{cc}\text { Inlet } & 0.706 \pm 0.512 \\ \text { Outlet } & 4.122 \pm 1.247 \\ \text { Lake } & 1.402 \pm 0.656 \\ \text { I vs. L } & \text { ns } \\ \text { I vs. O } & * \\ \text { L vs. O } & * \\ \text { Display } & 1.373 \pm 0.486^{*}\end{array}$

Final model same as in a

Final model same as in a
Final model same as in a

$$
\begin{gathered}
0.779 \pm 0.432 \\
3.560 \pm 0.943 \\
0.632 \pm 0.454 \\
\text { ns } \\
* \\
* * \\
2.863 \pm 0.773 \\
1.154 \pm 0.574 \\
0.954 \pm 0.516
\end{gathered}
$$$$
\text { Inlet }
$$

Outlet

Lake

I vs. L

I vs. O

L vs. O

Aggression

Inlet

Outlet

Lake

\section{ns}

ns

$$
\begin{aligned}
&-0.587 \pm 0.365 \\
&-2.029 \pm 0.709 \\
&-1.389 \pm 0.523 \\
& \text { ns } \\
& \text { ns } \\
& \text { ns }
\end{aligned}
$$

$-1.104 \pm 0.488$

$-1.161 \pm 0.502$

$-1.741 \pm 0.542$

ns

ns

ns
$-0.132 \pm 0.386$

$-1.574 \pm 0.557$

$-2.423 \pm 0.696$

ns

ns

。

$-1.091 \pm 0.519$

$-0.661 \pm 0.480$

$-2.378 \pm 0.674$

$*$

。

ns

$1.135 \pm 0.352^{* *}$

(d) Aggression and ASD

Final models same as in $c$ 


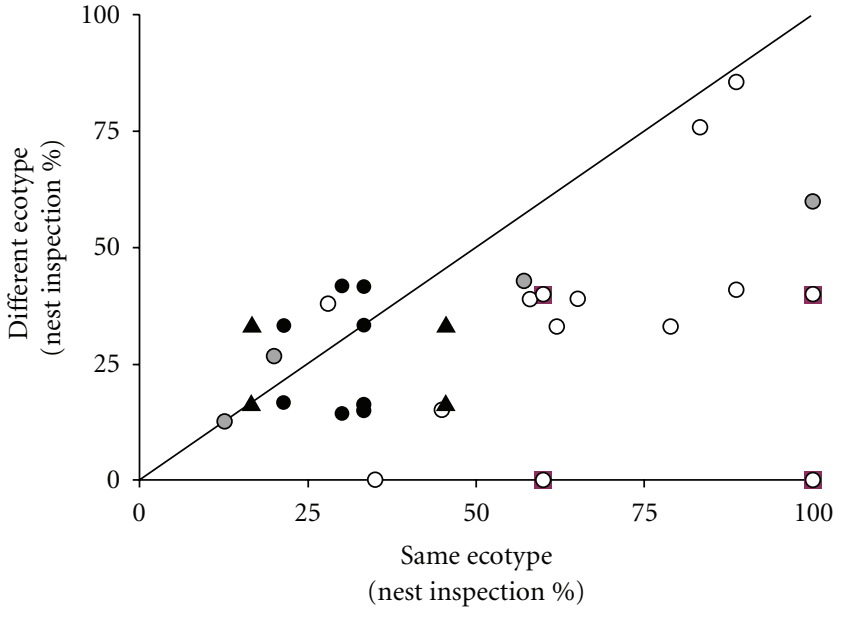

(a)

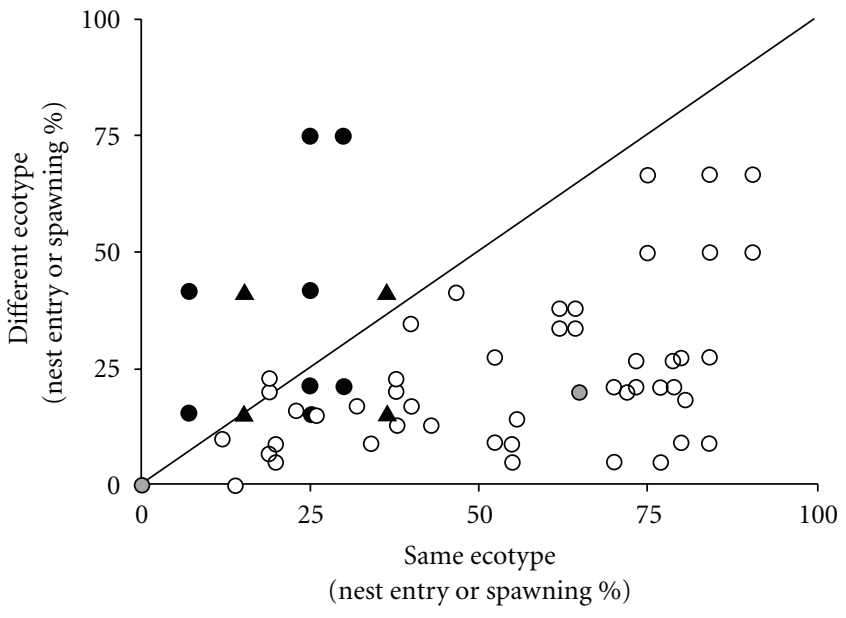

(b)

FIGURE 3: The relationship between same ecotype and different ecotype rates of (a) nest inspection and (b) nest entry or spawning in previously published threespine stickleback studies (open or grey circles) and current study (solid symbols). Open circles: wild-caught fish, grey circles: lab reared fish. Solid triangles: LO or OL combinations, which are treated as same ecotype due to phenotypic and genetic similarity. The line represents the 1:1 line of same and different ecotype matings. The details of the included studies are given in Table S1.

Misty system. This was not surprising for Lake versus Outlet fish given their phenotypic and genetic similarity, and so we do not further discuss that result. By contrast, the lack of PAMC between Lake and Inlet fish (which is also found for a different lab cohort and with a different experimental design, [29]) is surprising. That is, PAMC might be expected given (1) strong adaptive divergence in traits typically associated with mate choice in stickleback, in particular, body size and male behavior, (2) very low gene flow between these populations in nature, and (3) previous demonstrations of PAMC between other stickleback ecotypes (see Introduction). In the following sections, we first discuss factors that might influence this negative outcome, paying particular attention to experimental design and biological factors suggested to be important in theory and in stickleback and compare our studies with previous studies testing for PAMC in stickleback (Figure 3; Table S1). We then discuss how our results might relate to pressing questions in the study of ecological speciation.

4.1. Experimental Design. Perhaps the different outcome of our study versus previous work on other stickleback systems (Table S1) stems from differences in experimental design. First, our experiment might have lacked the statistical power necessary to detect PAMC. We do not think this is the case for three complementary reasons: (1) our statistical control for individual male variation should be a powerful design for detecting ecotype effects, (2) our sample sizes were similar to a number of previous studies that did detect PAMC (Table S1), and (3) the range of observed mating frequencies in our study fell within those seen in other studies (Figure 3 ). Moreover, although mate choice is clearly not random across the combinations, neither alternative ways of analyzing (see statistical analyses section) nor visual inspection of the data (Figure 1 and Figure S1) suggest any hint of positive assortative mating.
Second, laboratory mate choice experiments are always conducted under artificial conditions and thus exclude genotype-by-environment interactions that might be important in nature (e.g., $[49,60])$. Regardless, our experimental tanks and our no-choice design were very similar to those used in several previous studies that did detect PAMC in stickleback (Table S1), and we also did not detect PAMC using a different experimental design [29]. Our fish originated from multiple full-sib families, but we could not account statistically for family effects in our mate choice analyses (the data was insufficient to do so), and we can therefore not fully discount that family effects would have influenced our analyses. However, we think that any such effects would likely have been small compared to the ecotype differences, as supported also by the observation that divergence in traits typically mediating mate choice (behavior, body size, and body shape) remained strong even after accounting for family effects $[46,51]$. We therefore suggest that differences in experimental venue and design are unlikely to have caused the difference between our results and those documented in other stickleback systems.

Third, the present study and that of Raeymaekers et al. [29] both used common-garden fish, whereas nearly all previous stickleback studies have used wild-caught fish (Table S1, Figure 3, with an exception of [48] and [52]). When wild-caught fish are used, observed mating patterns could reflect environmental (nongenetic) effects, such as imprinting, prior experience, or some other form of phenotypic plasticity (e.g., [48-50]). Studies testing for PAMC would benefit from employing both common-garden and wild-caught individuals because this allows complementary inferences: common-garden individuals inform whether or not genetic divergence in mate choice has occurred, whereas wild-caught individuals might be more reflective of actual mating patterns in nature. In addition, complementary studies on PAMC in the wild would allow strong inferences about 
the true extent of PAMC. Combined experiments of this sort could make important contributions to the current debates about the importance of plasticity in promoting versus constraining ecological speciation and adaptive radiation [61-65].

4.2. The Role of Trait Divergence. In the context of ecological speciation, PAMC is expected to arise as a result of adaptive divergence in traits [66]. We consider two important factors that might contribute to this association. First, it has been argued that substantial progress toward ecological speciation, whether through PAMC or other reproductive barriers, requires either strong divergent selection on one ecological/trait dimension or modest-to-strong divergent selection along multiple ecological/trait dimensions [17]. Second, the evolution of mating isolation during ecological speciation is more likely when the traits undergoing adaptive divergence and the traits influencing mate choice are genetically associated $[67,68]$, so-called "magic traits" $[69,70]$.

With respect to the strength and dimensionality of divergent selection, Misty Lake-Inlet stickleback should be well endowed: they differ dramatically in a number of traits thought to be under divergent selection. These include body size, morphological traits related to predator defense (e.g., spine length and male color), foraging (e.g., mouth shape and gill raker number and length), swimming performance (e.g., sustained and burst swimming and maneuverability), and male reproductive behavior (e.g., nest construction, aggression, and courtship) $[29,37,38,40,46,51,53]$. Moreover, common-garden fish maintain divergence in these traits (see above citations), making them relevant in the present experiment. Given all of these trait differences, it seems unlikely that the apparent lack of PAMC is the result of insufficient divergent selection in either strength or dimensionality. Even strong and multifarious selection will not inevitably lead to PAMC. It is theoretically possible that lack of sufficient time for the evolution of mating isolation could contribute to the lack of PAMC. However, we do not think this is the case here, as divergence times based on neutral markers in the Misty system are similar to those in other lake/stream systems that show similar patterns of trait divergence $[30,32,38]$. Likewise, the time frame for colonization is similar in several types of stickleback ecotype pairs, which do show PAMC (i.e., after the last ice age, [21]).

With respect to magic traits, the most widely discussed possibility for stickleback is body size (Table S1 and references therein). As noted above, this trait differs markedly between Misty Lake and Inlet fish in the wild and in the lab. However, the suggested "mate with your own size" rule for stickleback (e.g., [7, 24]) was clearly absent in our experiment (Figure 2): males of all types tended to display more towards smaller (Inlet) females [51] and nest entry was more frequent when males were larger than females (Figure 2(b)). Possible explanations for these patterns are that (1) larger females might be avoided because they more frequently cannibalize the eggs in male nests [71], (2) larger males are of higher quality within both habitats (e.g., [72, 73]), and (3) females have retained ancestral preferences for large males or show a "supernormality" response (i.e., exaggerated version of a stimulus that causes a strong response) (e.g., [74, 75]).

Another possible magic trait would be male reproductive behavior, which is divergent between the ecotypes and influences mate choice. In particular, Lake and Outlet females tended to more frequently inspect the nests of more aggressive males, and Lake and Outlet males were the most aggressive. However, even this correlated divergence of male traits and female preferences was not sufficient to generate PAMC. It is of course possible that the role of male trait divergence and correlated female preference may only be apparent in more natural conditions. For example, if a more aggressive male courtship reflects his ability to defend his territory and offspring (e.g., [54, 71]), females might favor more aggressive males in the lake environments (i.e., high population densities and likely higher predation and egg raiding risk) in nature. Or maybe a distinction is needed between potential magic traits that are "trivial" versus "important," depending on just how much they contribute to mating isolation [70]. It is also possible that interactions between divergent natural and divergent sexual selection acting on traits, or selection acting in different directions in males and females, (e.g., $[11,15,25])$ may have undermined the evolution of PAMC.

4.3. Relevance for Key Questions in Ecological Speciation. Assuming that PAMC really is absent between Misty Lake and Inlet stickleback, as our work suggests, what might this, together with the frequent evidence for PAMC in other stickleback systems, tell us about ecological speciation? One question relates to the geographical context: close physical proximity between groups under divergent selection (i.e., sympatry or broad parapatry) can both constrain and promote the evolution of assortative mating. The potential constraint occurs when high gene flow hinders the development of a genetic association between adaptive traits and preferences for those traits (recombination: $[43,76]$ ). The potential promoter comes in the form of direct [77] or indirect (e.g., "reinforcement"; [78]) selection to avoid mating with the opposite type.

Previous work on stickleback suggests both possibilities. On the constraint side, high gene flow has clearly constrained adaptive divergence and progress toward ecological speciation in some lake/stream pairs $[31-33,41]$. On the promoting side, sympatry seems to enhance PAMC: PAMC is typically present between benthic and limnetic stickleback (Table S1), but it is higher when they come from the same lake $[5,71]$ than from different lakes $[5,9]$. In our case, the Lake and Inlet stickleback populations are parapatric, but our particular inlet sampling site was relatively far from the lake where gene flow from the lake population is probably very low [47]. This suggests that PAMC may be less likely to evolve in this essentially allopatric situation. This hypothesis could be tested in lake/stream systems by conducting experiments with stream stickleback both from very near and far to the lake.

Another question relates to the number and type of reproductive barriers that drive ecological speciation [79, $80]$. That is, ecological speciation might sometimes be driven 
by only a single barrier that renders all other barriers unimportant. Such a barrier would have to be strong and symmetric and would most likely occur early in the life cycle. Putative examples of such barriers include habitat choice (e.g., $[81,82]$ ), divergent reproductive timing (e.g., $[83,84]$ ), strong viability selection against migrants (e.g., $[79,85]$ ), or postzygotic incompatibilities (e.g., [86]). Alternatively, ecological speciation could be the result of the joint evolution of many reproductive barriers that are strong and symmetric only in aggregate. Along this vein, a number of studies have documented many reproductive barriers between diverging taxa, such as in Mimulus monkeyflowers [87] and Timema walking sticks [18]. However, it remains unclear to what extent these multiple barriers contributed to reproductive isolation during the course of speciation, as opposed to accumulating incidentally or after the fact.

Work on the benthic/limnetic stickleback system suggests that multiple reproductive barriers help to maintain reproductive isolation $([21,22])$. However, the relative importance of each of these barriers during the process of divergence is uncertain. For the lake/stream stickleback system, the problem is the opposite: no strong barriers have been found despite limited gene flow in nature. Instead, the various potential barriers investigated so far seem asymmetric and certainly incomplete, including limited dispersal ability (distance and beaver dams), habitat choice [38], selection against migrants ([38]; K. Räsänen and A.P. Hendry, unpubl. data), temporal isolation (J.-S. Moore and K. Räsänen, unpubl. data), and sexual selection against hybrids [29]. No clear evidence exists either for the role of postzygotic incompatibilities, as fertilization success and survival to hatching are high in hybrids ([37], Räsänen, K., pers. obs.). Overall reproductive isolation might therefore reflect a combination of many different partial reproductive barriers.

Lake/stream stickleback thus present us with a conundrum that could ultimately be very informative of the factors that influence progress toward ecological speciation. Clearly more studies, replicated over multiple systems, are needed on PAMC and other potential reproductive barriers. Of particular utility is the availability of many independently derived parapatric population pairs that show various levels of geographical separation, adaptive divergence, and gene flow [31-33]. Lake/stream stickleback therefore provide an opportunity to quantify the relative importance and symmetry of multiple potential reproductive barriers during the early stages of divergence $[79,80]$ as well as interactions between ecology and the geographical context in the development of these barriers (e.g., $[15,19,88])$. This, and studies on other taxa with similar levels of variation and replication, together with tests of PAMC in wild and common garden populations, should take us a step closer to understanding the key features of ecological speciation.

\section{Acknowledgments}

The authors thank Jean-Sebastien Moore, Martin Turcotte, Angeliina Alopaeus, and the Friends of the Marble River for help in the field. Laboratory work was facilitated or aided by Jihane Giraud, Jaclyn Paterson, Kate Hudson, Dolph
Schluter, Karen Faller, and the personnel of the McGill Phytotron. All experiments were conducted in accordance with animal use protocols at McGill University. The study was funded by Swedish Research Council (to K. Räsänen) and the Natural Sciences and Engineering Research Council of Canada (to A. P. Hendry and L. J. Chapman).

\section{References}

[1] D. Schluter, The Ecology of Adaptive Radiation, Oxford University Press, Oxford, UK, 2000.

[2] H. D. Rundle and P. Nosil, "Ecological speciation," Ecology Letters, vol. 8, no. 3, pp. 336-352, 2005.

[3] D. J. Funk, P. Nosil, and W. J. Etges, "Ecological divergence exhibits consistently positive associations with reproductive isolation across disparate taxa," Proceedings of the National Academy of Sciences of the United States of America, vol. 103, no. 9, pp. 3209-3213, 2006.

[4] D. J. Funk, "Isolating a role for natural selection in speciation: host adaptation and sexual isolation in Neochlamisus bebbianae leaf beetles," Evolution, vol. 52, no. 6, pp. 1744-1759, 1998.

[5] H. D. Rundle, L. Nagel, J. W. Boughman, and D. Schluter, "Natural selection and parallel speciation in sympatric sticklebacks," Science, vol. 287, no. 5451, pp. 306-308, 2000.

[6] P. Nosil, B. J. Crespi, and C. P. Sandoval, "Host-plant adaptation drives the parallel evolution of reproductive isolation," Nature, vol. 417, no. 6887, pp. 440-443, 2002.

[7] J. S. McKinnon, S. Mori, B. K. Blackman et al., "Evidence for ecology's role in speciation," Nature, vol. 429, no. 6989, pp. 294-298, 2004.

[8] J. W. Boughman, H. D. Rundle, and D. Schluter, "Parallel evolution of sexual isolation in sticklebacks," Evolution, vol. 59, no. 2, pp. 361-373, 2005.

[9] T. H. Vines and D. Schluter, "Strong assortative mating between allopatric sticklebacks as a by-product of adaptation to different environments," Proceedings of the Royal Society B, vol. 273, no. 1589, pp. 911-916, 2006.

[10] R. B. Langerhans, M. E. Gifford, and E. O. Joseph, "Ecological speciation in Gambusia fishes," Evolution, vol. 61, no. 9, pp. 2056-2074, 2007.

[11] J. Ellers and C. L. Boggs, "The evolution of wing color: male mate choice opposes adaptive wing color divergence in Colias butterflies," Evolution, vol. 57, no. 5, pp. 1100-1106, 2003.

[12] H. D. Rundle, "Divergent environments and population bottlenecks fail to generate premating isolation in Drosophila pseudoobscura," Evolution, vol. 57, no. 11, pp. 2557-2565, 2003.

[13] A. Brelsford and D. E. Irwin, "Incipient speciation despite little assortative mating: the yellow-rumped warbler hybrid zone," Evolution, vol. 63, no. 12, pp. 3050-3060, 2009.

[14] L. Kwan and H. D. Rundle, "Adaptation to desiccation fails to generate pre- and postmating isolation in replicate Drosophila melanogaster laboratory populations," Evolution, vol. 64, no. 3, pp. 710-723, 2010.

[15] A. K. Schwartz, D. J. Weese, P. Bentzen, M. T. Kinnison, and A. P. Hendry, "Both geography and ecology contribute to mating isolation in guppies," PLOS ONE, vol. 5, no. 12, Article ID e15659, 2010.

[16] A. P. Hendry, "Ecological speciation! Or the lack thereof?" Canadian Journal of Fisheries and Aquatic Sciences, vol. 66, no. 8, pp. 1383-1398, 2009. 
[17] P. Nosil, L. J. Harmon, and O. Seehausen, "Ecological explanations for (incomplete) speciation," Trends in Ecology and Evolution, vol. 24, no. 3, pp. 145-156, 2009.

[18] P. Nosil, "Divergent host plant adaptation and reproductive isolation between ecotypes of Timema cristinae walking sticks," American Naturalist, vol. 169, no. 2, pp. 151-162, 2007.

[19] E. B. Rosenblum and L. J. Harmon, "'Same same but different": replicated ecological speciation at white sands," Evolution, vol. 65, no. 4, pp. 946-960, 2011.

[20] M. A. Bell and S. A. Foster, The Evolutionary Biology of the Threespine Stickleback, Oxford University Press, New York, NY, USA, 1994.

[21] J. S. McKinnon and H. D. Rundle, "Speciation in nature: the threespine stickleback model systems," Trends in Ecology and Evolution, vol. 17, no. 10, pp. 480-488, 2002.

[22] A. P. Hendry, D. I. Bolnick, D. Berner, and C. L. Peichel, "Along the speciation continuum in sticklebacks," Journal of Fish Biology, vol. 75, no. 8, pp. 2000-2036, 2009.

[23] M. S. Ridgway and J. D. McPhail, "Ecology and evolution of sympatric sticklebacks (Gasterosteus): mate choice and reproductive isolation in the Enos Lake species pair," Canadian Journal of Zoology, vol. 62, no. 9, pp. 1813-1818, 1984.

[24] L. Nagel and D. Schluter, "Body size, natural selection, and speciation in sticklebacks," Evolution, vol. 52, no. 1, pp. 209218,1998

[25] G. M. Kozak, M. Reisland, and J. W. Boughmann, "Sex differences in mate recognition and conspecific preference in species with mutual mate choice," Evolution, vol. 63, no. 2, pp. 353-365, 2009.

[26] D. E. Hay and J. D. McPhail, "Mate selection in threespine sticklebacks," Canadian Journal of Zoology, vol. 53, pp. 441450, 1975.

[27] G. Á. Ólafsdóttir, M. G. Ritchie, and S. S. Snorrason, "Positive assortative mating between recently described sympatric morphs of Icelandic sticklebacks," Biology Letters, vol. 2, no. 2, pp. 250-252, 2006.

[28] F. C. Jones, C. Brown, and V. A. Braithwaite, "Lack of assortative mating between incipient species of stickleback from a hybrid zone," Behaviour, vol. 145, no. 4-5, pp. 463-484, 2008.

[29] J. A. M. Raeymaekers, M. Boisjoly, L. Delaire, D. Berner, K. Räsänen, and A. P. Hendry, "Testing for mating isolation between ecotypes: laboratory experiments with lake, stream and hybrid stickleback," Journal of Evolutionary Biology, vol. 23, no. 12, pp. 2694-2708, 2010.

[30] C. E. Thompson, E. B. Taylor, and J. D. Mcphail, "Parallel evolution of lake-stream pairs of threespine sticklebacks (Gasterosteus) inferred from mitochondrial DNA variation," Evolution, vol. 51, no. 6, pp. 1955-1965, 1997.

[31] A. P. Hendry and E. B. Taylor, "How much of the variation in adaptive divergence can be explained by gene flow? An evaluation using lake-stream stickleback pairs," Evolution, vol. 58, no. 10, pp. 2319-2331, 2004.

[32] D. Berner, A. C. Grandchamp, and A. P. Hendry, "Variable progress toward ecological speciation in parapatry: stickleback across eight lake-stream transitions," Evolution, vol. 63, no. 7, pp. 1740-1753, 2009.

[33] D. Berner, M. Roesti, A. P. Hendry, and W. Salzburger, "Constraints on speciation suggested by comparing lake-stream stickleback divergence across two continents," Molecular Ecology, vol. 19, no. 22, pp. 4963-4978, 2010.

[34] G. E. E. Moodie, "Morphology, life history and ecology of an unusual stickleback (Gasterosteus aculeatus) in the Queen Charlotte Islands, Canada," Canadian Journal of Zoology, vol. 50, pp. 721-732, 1972.
[35] G. E. E. Moodie, "Predation, natural selection and adaptation in an unusual threespine stickleback," Heredity, vol. 28, pp. 155-167, 1972.

[36] T. E. Reimchen, E. M. Stinson, and J. S. Nelson, "Multivariate differentiation of parapatric and allopatric populations of threespine stickleback in the Sangan River watershed, Queen Charlotte Islands," Canadian Journal of Zoology, vol. 63, pp. 2944-2951, 1985.

[37] P. A. Lavin and J. D. McPhail, "Parapatric lake and stream sticklebacks on northern Vancouver Island: disjunct distribution or parallel evolution?" Canadian Journal of Zoology, vol. 71, no. 1, pp. 11-17, 1993.

[38] A. P. Hendry, E. B. Taylor, and J. D. McPhail, "Adaptive divergence and the balance between selection and gene flow: lake and stream stickleback in the Misty system," Evolution, vol. 56, no. 6, pp. 1199-1216, 2002.

[39] D. Berner, D. C. Adams, A. C. Grandchamp, and A. P. Hendry, "Natural selection drives patterns of lake-stream divergence in stickleback foraging morphology," Journal of Evolutionary Biology, vol. 21, no. 6, pp. 1653-1665, 2008.

[40] A. P. Hendry, K. Hudson, J. A. Walker, K. Räsänen, and L. J. Chapman, "Genetic divergence in morphology-performance mapping between Misty Lake and inlet stickleback," Journal of Evolutionary Biology, vol. 24, no. 1, pp. 23-35, 2011.

[41] J. S. Moore, J. L. Gow, E. B. Taylor, and A. P. Hendry, "Quantifying the constraining influence of gene flow on adaptive divergence in the lake-stream threespine stickleback system," Evolution, vol. 61, no. 8, pp. 2015-2026, 2007.

[42] K. Räsänen and A. P. Hendry, "Disentangling interactions between adaptive divergence and gene flow when ecology drives diversification," Ecology Letters, vol. 11, no. 6, pp. 624636, 2008.

[43] S. Gavrilets and A. Vose, "Dynamic patterns of adaptive radiation," Proceedings of the National Academy of Sciences of the United States of America, vol. 102, no. 50, pp. 18040-18045, 2005.

[44] X. Thibert-Plante and A. P. Hendry, "Five questions on ecological speciation addressed with individual-based simulations," Journal of Evolutionary Biology, vol. 22, no. 1, pp. 109-123, 2009.

[45] X. Thibert-Plante and A. P. Hendry, "When can ecological speciation be detected with neutral loci?" Molecular Ecology, vol. 19, no. 11, pp. 2301-2314, 2010.

[46] D. M. T. Sharpe, K. Räsänen, D. Berner, and A. P. Hendry, "Genetic and environmental contributions to the morphology of lake and stream stickleback: implications for gene flow and reproductive isolation," Evolutionary Ecology Research, vol. 10, no. 6, pp. 849-866, 2008.

[47] J. S. Moore and A. P. Hendry, "Both selection and gene flow are necessary to explain adaptive divergence: evidence from clinal variation in stream stickleback," Evolutionary Ecology Research, vol. 7, no. 6, pp. 871-886, 2005.

[48] G. M. Kozak, M. L. Head, and J. W. Boughman, "Sexual imprinting on ecologically divergent traits leads to sexual isolation in sticklebacks," Proceedings of the Royal Society B, vol. 278, no. 1718, pp. 2604-2610, 2011.

[49] G. M. Kozak and J. W. Boughman, "Learned conspecific mate preference in a species pair of sticklebacks," Behavioral Ecology, vol. 20, no. 6, pp. 1282-1288, 2009.

[50] J. H. Jennings and W. J. Etges, "Species hybrids in the laboratory but not in nature: a reanalysis of premating isolation between Drosophila arizonae and D. mojavensis," Evolution, vol. 64 , no. 2, pp. 587-598, 2010. 
[51] M. Delcourt, K. Räsänen, and A. P. Hendry, "Genetic and plastic components of divergent male intersexual behavior in Misty lake/stream stickleback," Behavioral Ecology, vol. 19, no. 6, pp. 1217-1224, 2008.

[52] T. Hatfield and D. Schluter, "A test for sexual selection on hybrids of two sympatric sticklebacks," Evolution, vol. 50, no. 6, pp. 2429-2434, 1996.

[53] J. A. M. Raeymaekers, L. Delaire, and A. P. Hendry, "Genetically based differences in nest characteristics between lake, inlet, and hybrid threespine stickleback from the misty system, British Columbia, Canada," Evolutionary Ecology Research, vol. 11, no. 6, pp. 905-919, 2009.

[54] H. D. Rundle and D. Schluter, "Reinforcement of stickleback mate preferences: sympatry breeds contempt," Evolution, vol. 52, no. 1, pp. 200-208, 1998.

[55] J. D. McPhail and D. E. Hay, "Differences in male courtship in freshwater and marine sticklebacks," Canadian Journal of Zoology, vol. 61, pp. 292-297, 1983.

[56] S. A. Foster, "Understanding the evolution of behavior in threespine stickleback: the value of geographic variation," Behaviour, vol. 132, no. 15-16, pp. 1107-1129, 1995.

[57] M. Ishikawa and S. Mori, "Mating success and male courtship behaviors in three populations of the threespine stickleback," Behaviour, vol. 137, no. 7-8, pp. 1065-1080, 2000.

[58] SAS Institute, SAS/STAT® 9.2 User's Guide, SAS Institute, Cary, NC, USA, 2008.

[59] K. P. Burnham and D. R. Andersson, Model Selection and Multimodel Inference: A Practical Information-Theoretical Approach, Springer, New York, NY, USA, 2nd edition, 2002.

[60] E. Lewandowski and J. Boughman, "Effects of genetics and light environment on colour expression in threespine sticklebacks," Biological Journal of the Linnean Society, vol. 94, no. 4, pp. 663-673, 2008.

[61] M. J. West-Eberhardt, Developmental Plasticity and Evolution, Oxford University Press, New York, NY, USA, 2003.

[62] E. Crispo, "Modifying effects of phenotypic plasticity on interactions among natural selection, adaptation and gene flow," Journal of Evolutionary Biology, vol. 21, no. 6, pp. 1460 1469, 2008.

[63] R. Svanbäck, M. Pineda-Krch, and M. Doebeli, "Fluctuating population dynamics promotes the evolution of phenotypic plasticity," American Naturalist, vol. 174, no. 2, pp. 176-189, 2009.

[64] D. W. Pfennig, M. A. Wund, E. C. Snell-Rood, T. Cruickshank, C. D. Schlichting, and A. P. Moczek, "Phenotypic plasticity's impacts on diversification and speciation," Trends in Ecology and Evolution, vol. 25, no. 8, pp. 459-467, 2010.

[65] X. Thibert-Plante and A. P. Hendry, "The consequences of phenotypic plasticity for ecological speciation," Journal of Evolutionary Biology, vol. 24, no. 2, pp. 326-342, 2011.

[66] D. Schluter, "Ecology and the origin of species," Trends in Ecology and Evolution, vol. 16, no. 7, pp. 372-380, 2001.

[67] A. S. Kondrashov and F. A. Kondrashov, "Interactions among quantitative traits in the course of sympatric speciation," Nature, vol. 400, no. 6742, pp. 351-354, 1999.

[68] J. D. Fry, "Multilocus models of sympatric speciation: bush versus rice versus felsenstein," Evolution, vol. 57, no. 8, pp. 1735-1746, 2003.

[69] S. Gavrilets, Fitness Landscapes and the Origin of Species, Princeton University Press, Princeton, NJ, USA, 2004.

[70] M. R. Servedio, G. S. V. Doorn, M. Kopp, A. M. Frame, and P. Nosil, "Magic traits in speciation: "magic" but not rare?"
Trends in Ecology and Evolution, vol. 26, no. 8, pp. 389-397, 2011.

[71] A. Y. K. Albert and D. Schluter, "Reproductive character displacement of male stickleback mate preference: reinforcement or direct selection?" Evolution, vol. 58, no. 5, pp. 1099-1107, 2004.

[72] S. B. M. Kraak and T. C. M. Bakker, "Mutual mate choice in sticklebacks: attractive males choose big females, which lay big eggs," Animal Behaviour, vol. 56, no. 4, pp. 859-866, 1998.

[73] U. Candolin and H. R. Voigt, "Correlation between male size and territory quality: consequence of male competition or predation susceptibility?” Oikos, vol. 95, no. 2, pp. 225-230, 2001.

[74] G. E. E. Moodie, "Why asymmetric mating preferences may not show the direction of evolution," Evolution, vol. 36, pp. 1096-1097, 1982.

[75] W. J. Rowland, "Mate choice and the supernormality effect in female sticklebacks (Gasterosteus aculeatus)," Behavioral Ecology and Sociobiology, vol. 24, no. 6, pp. 433-438, 1989.

[76] J. Felsenstein, "Skepticism towards Santa Rosalia, or why are there so few kinds of animals?" Evolution, vol. 35, pp. 124-138, 1981.

[77] M. R. Servedio, "Beyond reinforcement: the evolution of premating isolation by direct selection on preferences and postmating, prezygotic incompatibilities," Evolution, vol. 55, no. 10, pp. 1909-1920, 2001.

[78] M. R. Servedio and M. A. F. Noor, "The role of reinforcement in speciation: theory and data," Annual Review of Ecology, Evolution, and Systematics, vol. 34, pp. 339-364, 2003.

[79] P. Nosil, T. H. Vines, and D. J. Funk, "Perspective: reproductive isolation caused by natural selection against immigrants from divergent habitats," Evolution, vol. 59, no. 4, pp. 705-719, 2005.

[80] D. B. Lowry, J. L. Modliszewski, K. M. Wright, C. A. Wu, and J. H. Willis, "Review. The strength and genetic basis of reproductive isolating barriers in flowering plants," Philosophical Transactions of the Royal Society B, vol. 363, no. 1506, pp. 3009-3021, 2008.

[81] J. L. Feder, S. B. Opp, B. Wlazlo, K. Reynolds, W. Go, and S. Spisak, "Host fidelity is an effective premating barrier between sympatric races of the apple maggot fly," Proceedings of the National Academy of Sciences of the United States of America, vol. 91, no. 17, pp. 7990-7994, 1994.

[82] D. J. Bolnick, L. Snowberg, C. Patenia, O. L. Lau, W. E. Stutz, and T. Ingram, "Habitat choice contributes to adaptive divergence between lake and stream populations of three-spine stickleback," Evolution, vol. 63, pp. 2004-2016, 2009.

[83] R. D. Alexander and R. S. Bigelow, "Allochronic speciation in field crickets, and a new species, Acheta veletis," Evolution, vol. 14, pp. 334-346, 1960.

[84] V. L. Friesen, A. L. Smith, E. Gómez-Díaz et al., "Sympatric speciation by allochrony in a seabird," Proceedings of the National Academy of Sciences of the United States of America, vol. 104, no. 47, pp. 18589-18594, 2007.

[85] S. Via, A. C. Bouck, and S. Skillman, "Reproductive isolation between divergent races of pea aphids on two hosts. II. Selection against migrants and hybrids in the parental environments," Evolution, vol. 54, no. 5, pp. 1626-1637, 2000.

[86] D. C. Presgraves, L. Balagopalan, S. M. Abmayr, and H. A. Orr, "Adaptive evolution drives divergence of a hybrid inviability gene between two species of Drosophila," Nature, vol. 423, no. 6941, pp. 715-719, 2003. 
[87] J. Ramsey, H. D. Bradshaw, and D. W. Schemske, "Components of reproductive isolation between the monkeyflowers Mimulus lewisii and M. cardinalis (Phrymaceae)," Evolution, vol. 57, no. 7, pp. 1520-1534, 2003.

[88] R. K. Butlin, J. Galindo, and J. W. Grahame, "Review. Sympatric, parapatric or allopatric: the most important way to classify speciation?" Philosophical Transactions of the Royal Society B, vol. 363, no. 1506, pp. 2997-3007, 2008. 

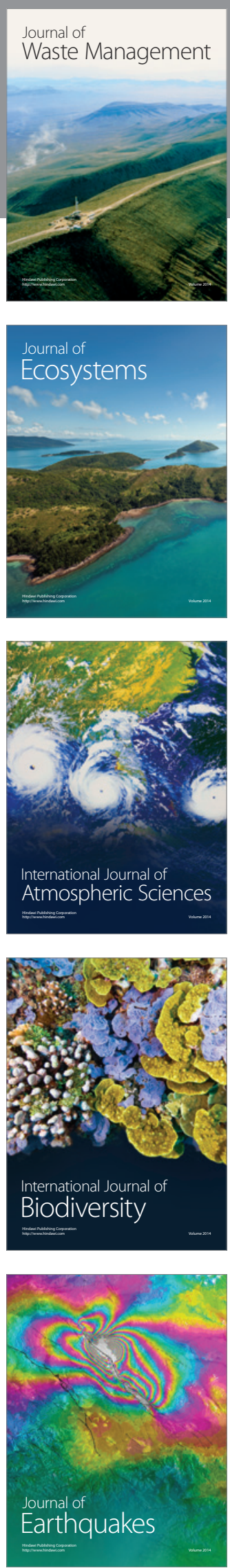
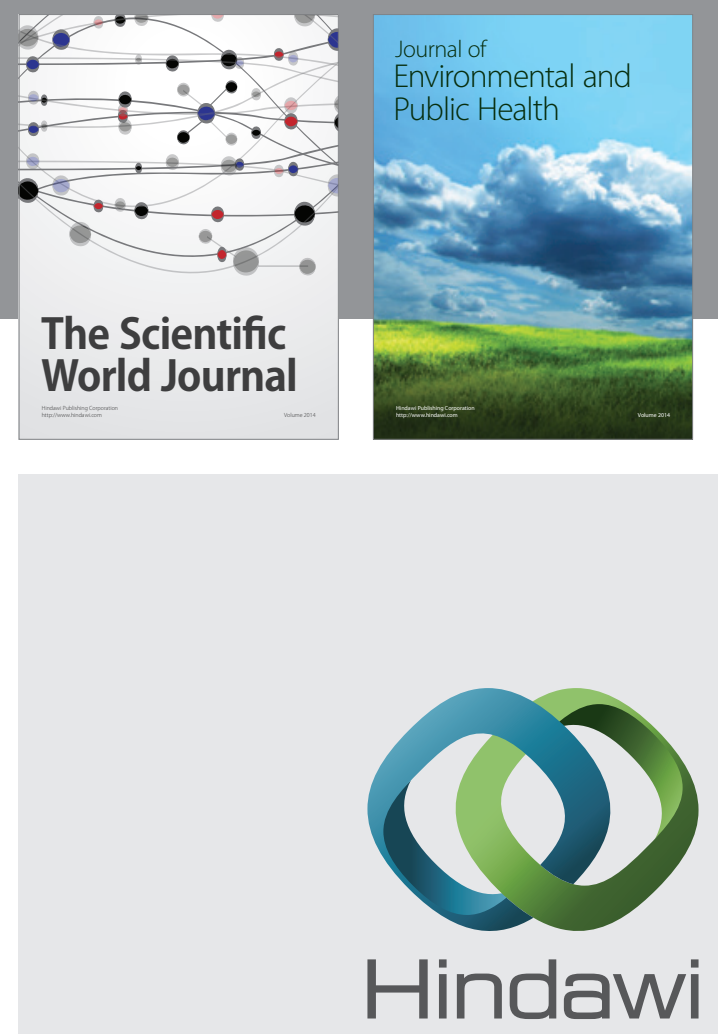

Submit your manuscripts at

http://www.hindawi.com
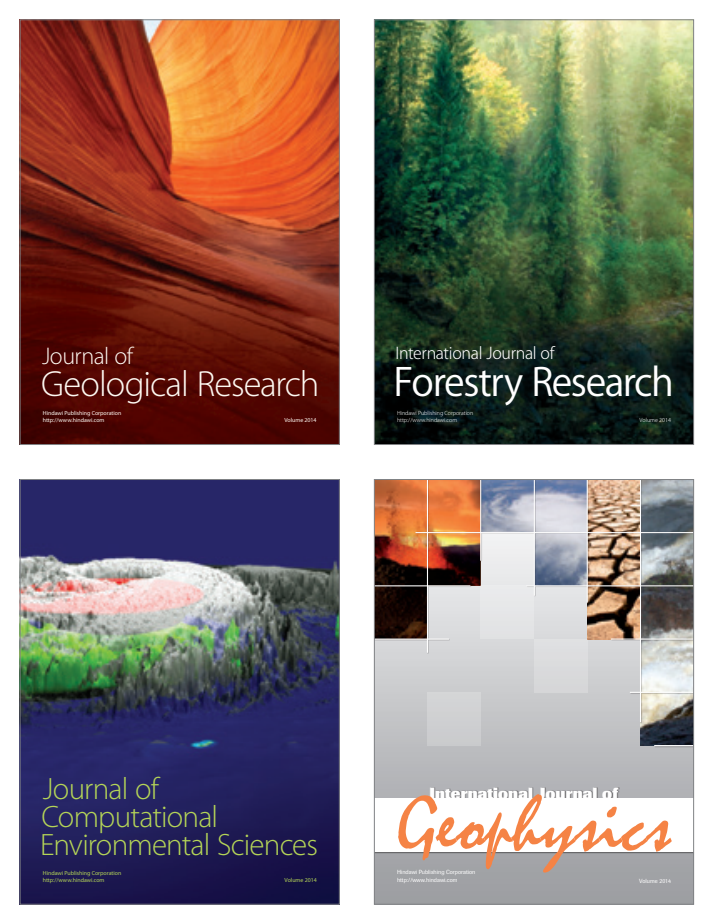
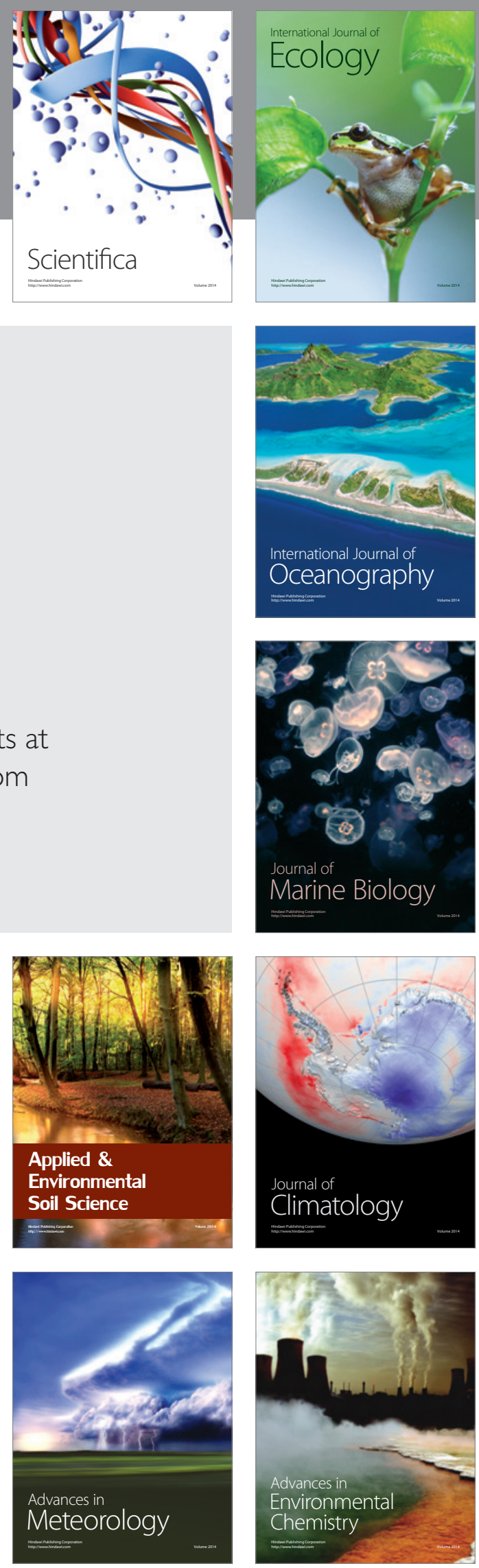